\title{
Mucoepidermoid carcinoma of the salivary glands revisited with special reference to histologic grading and CRTC1/3-MAML2 genotyping
}

\author{
André Fehr ${ }^{1}$ (1) - Sarah Werenicz ${ }^{2}$ Pietro Trocchi ${ }^{3} \cdot$ Markus Falk $^{4}$ (1) $\cdot$ Reinhard E. Friedrich ${ }^{2}$ (1) - Angelika Stammler ${ }^{5}$. \\ Andreas Stang ${ }^{3,6}\left(\right.$ Florian Oesterling $^{6}\left(\right.$ Caura Khil $^{6} \cdot$ Göran Stenman $^{1}(\mathbb{D}) \cdot$ Werner Böcker $^{7} \cdot$ Katharina Tiemann $^{4}$. \\ Thomas Löning ${ }^{7}$ (1)
}

Received: 12 March 2021 / Revised: 8 June 2021 / Accepted: 19 June 2021 / Published online: 7 July 2021

(c) The Author(s) 2021

\begin{abstract}
Mucoepidermoid carcinoma (MEC) is the most common carcinoma of the salivary glands. Here, we have used two large patient cohorts with MECs comprising 551 tumors to study clinical, histological, and molecular predictors of survival. One cohort ( $\mathrm{n}=167)$, with known CRCT1/3-MAML2 fusion status, was derived from the Hamburg Reference Centre (HRC; graded with the AFIP and Brandwein systems) and the other $(\mathrm{n}=384)$ was derived from the population-based Cancer Registry of North Rhine-Westphalia (LKR-NRW; graded with the AFIP system). The reliability of both the AFIP and Brandwein grading systems was excellent $(\mathrm{n}=155)$. The weighted kappa for inter-rater agreement was 0.81 (95\% CI 0.65-0.97) and 0.83 (95\% CI 0.71-0.96) for the AFIP and Brandwein systems, respectively. The 5-year relative survival was 79.7\% (95\% CI 73.2-86.2\%). Although the Brandwein system resulted in a higher rate of G3-MECs, survival in G3-tumors (AFIP or Brandwein grading) was markedly worse than in G1/G2-tumors. Survival in > T2 tumors was markedly worse than in those with lower T-stage. Also, fusion-negative MECs had a worse 5-year progression-free survival. The frequency of fusionpositive MECs in the HRC cohort was 78.4\%, of which the majority (86.7\%) was G1/G2-tumors. In conclusion, the AFIP and Brandwein systems are useful in estimating prognosis and to guide therapy for G3-MECs. However, their significance regarding young age ( $\leq 30$ years) and location-dependent heterogeneity of in particular G2-tumors is more questionable. We conclude that CRTC1/3-MAML2 testing is a useful adjunct to histologic scoring of MECs and for pinpointing tumors with poor prognosis with higher precision, thus avoiding overtreatment.
\end{abstract}

Keywords CRTC1-MAML2 - Gene fusion · Head and neck neoplasms · Mucoepidermoid carcinoma; Neoplasm grading · Observer variation

\section{Abbreviations \\ MEC Mucoepidermoid carcinoma(s) \\ HRC Hamburg Salivary Gland Reference Centre, Germany}

André Fehr, Sarah Werenicz and Pietro Trocchi are equal authorship

André Fehr

andre.fehr@gu.se

1 Sahlgrenska Center for Cancer Research, Department of Pathology, Sahlgrenska University Hospital, University of Gothenburg, Gothenburg, Sweden

2 Department of Oral and Craniomaxillofacial Surgery, Eppendorf University Hospital, University of Hamburg, Hamburg, Germany

3 Institute of Medical Informatics, Biometry and Epidemiology (IMIBE), University Hospital Essen, Essen, Germany
4 Institute for Hematopathology, Hamburg, Germany

5 Faculty of Medicine, Justus-Liebig-University Giessen, Giessen, Germany

6 Cancer Registry North Rhine-Westphalia, Bochum, Germany

7 Gerhard Seifert Reference-Center - Hansepathnet, Hamburg, Germany 


$\begin{array}{ll}\text { LKR-NRW } & \begin{array}{l}\text { Cancer Registry of North Rhine-Westphalia, } \\ \text { Germany }\end{array} \\ \text { PFS } & \text { Progression-free survival } \\ \text { SE } & \text { Standard error }\end{array}$

\section{Introduction}

Mucoepidermoid carcinoma (MEC) is the most common salivary gland malignancy especially in young adults and children $[1,2]$. The tumor is typically composed of mucinous, intermediate (clear cell), and squamoid cells forming cystic or solid patterns [2]. The predominant variant (i.e., cystic and differentiated) usually follows a favorable clinical course after surgical resection [3]. In contrast, the less common variant with a more solid architecture, necrosis, and prominent cellular/nuclear atypia is prone to invasive growth and metastases $[4,5]$. Based on their histological appearances, pathologists at the Armed Forces Institute of Pathology (AFIP) established the first grading system for salivary MECs [6, 7]. However, this system and its later modifications continue to evoke critical reservations concerning the identification of true high-risk MECs [8].

Today, the two most frequently employed (semiquantitative) grading systems, the AFIP and Brandwein systems [9, 10], divide MEC into low- (G1), intermediate- (G2), and high-grade (G3) tumors assigning points to specific histologic features. Importantly, scoring of the same tumor is not always concordant between the two systems, especially regarding the distinction between G2- and G3-tumors. In contrast to AFIP, the Brandwein system weights different aspects of tumor invasion higher. Although the latter system is recommended by the latest WHO Classification of Head and Neck Tumors [2], there is still some debate about its clinical implications, in particular the risk of overscoring and thus overtreatment.

The role of molecular testing of salivary gland tumors was recently reviewed by Skalova and co-workers [11]. Previous studies have shown that the underlying molecular mechanism of MEC development is a recurrent $\mathrm{t}(11 ; 19)$ translocation [12] resulting in a CRTC1-MAML2 gene fusion $[13,14]$. The fusion occurs at a very high frequency in MEC, mainly in G1- and G2-, and rarely in G3-tumors [15-17]. The discovery of this gene fusion and the rare variant fusion, CRTC3-MAML2 [18], have refined the definition of this entity. Although early clinical studies claimed that patients with CRTC1/3-MAML2-negative MECs have a worse prognosis $[15-17,19,20]$, this issue has not been finally resolved $[2,21]$.

The aim of this study was to investigate clinical, histological, and molecular predictors of survival of MEC patients in two large cohorts. We studied the association between age, sex, location, pT staging, grading, and the presence of the
CRTC1/3-MAML2 fusion. We also assessed the inter-rater variability of the AFIP and Brandwein grading systems and their impact on survival.

\section{Materials and methods}

\section{Patient material}

The Hamburg Salivary Gland Reference Centre cohort The local Ethics Review Board approved the study in November 2017 (PV5412). Pathologists from the Hamburg Salivary Gland Reference Centre (HRC), in charged of the second opinion diagnoses of salivary gland tumors (TL and WB), routinely review all histological slides submitted by external laboratories. Whenever necessary, the HRC laboratory performs additional stainings (H\&E, PAS, Alcian blue, and rarely immunohistochemical stainings). A series of 167 MECs of the major and minor salivary glands with adequate tumor material available, diagnosed between 2007 and 2020 was identified in the HRC archive. All cases were tested for the CRTC1/3-MAML2 fusions as part of the routine diagnostic procedures. Clinical information for these cases were retrieved from the medical records at HRC or from the pathologist primarily in charge of the patient. Survival data was available for 60 patients. For 43 patients, the primary diagnosis dated back more than 5 years.

The population-based Cancer Registry of North Rhine-Westphalia cohort The population-based cancer registry of North Rhine-Westphalia (LKR-NRW) in Germany represents the largest population-based cancer registry in Europe covering a population of 18.1 million inhabitants. All cancers of inhabitants of the Federal State of North Rhine-Westphalia are reported to LKR-NRW. Reporting of incident cancers occurs mainly through pathology reports, with an estimated completeness of cancer registration in 2016 of more than $90 \%$ [22]. We extracted all cases diagnosed between 2007 and 2017 with incident tumors morphologically coded as 8430/3 (MEC) and topographically coded as C00-C09 (malignant neoplasms of minor salivary glands, the parotid gland, and unspecified major salivary glands) according to the International Classification of Diseases for Oncology (ICD-O-3). The final population-based cohort included 384 MECs, for which all original reports were reviewed. Tumor grade was available in 332 cases (grading according to the AFIP system). Ninety-two of the 384 (24\%) MECs were from the large Institutes of Pathology at the Universities of Münster, Bochum, Essen, Düsseldorf, Aachen, Köln, and Bonn. These centers have their own internal system for second opinions, and cases from these centers were therefore only randomly reviewed by the HRC experts. Cases from 
smaller institutions were reviewed by the HRC experts on demand. This was especially true for minor salivary gland MECs.

\section{Histologic reevaluation and fusion gene screening}

We evaluated the inter-rater agreement by a blinded pathological reevaluation of 155 cases, exerted by two head and neck pathologists (TL and WB) according to the AFIP and Brandwein grading systems $[9,10]$. The TNM-stage was defined based on the 8th edition of the AJCC guidelines [23]. All cases were screened for the CRTC1-MAML2 fusion, by RT-PCR and sequenced as previously described [16]. In addition to CRTC1$M A M L 2$ fusion transcripts, our PCR assay also detects rare CRTC3-MAML2 transcripts appearing as PCR prodcucts of atypical size. All of the latter PCR products were analyzed by direct Sanger sequencing [18].

\section{Statistical methods}

To assess the inter-rater agreement between the pathologists grading according to both the AFIP and the Brandwein systems, we estimated observed and chance-corrected agreements (weighted kappa), including 95\% confidence intervals, based on a dichotomization of the pathological assessments (low-/ intermediate-grade, G1/G2 versus high-grade, G3). For comparison of prevalences, we calculated prevalence ratios with 95\% confidence intervals.

For the HRC cohort, we estimated the 5-year cumulative progression-free survival (PFS) and the corresponding standard errors. Survival time was calculated as the time interval between the date of the first treatment and the date of disease progression. Patients without disease progression were rightcensored at the date of death or the date of the last follow-up visit. For the LKR-NRW cohort, we calculated sex-stratified age-standardized incidence rates (age standard: old European Standard population) for the overall period 2007-2017 including the corresponding standard error (SE). The 5-year absolute and relative survival was estimated by tumor grade using the period approach [24]. We computed age-standardized relative survival estimates according to the approach of Brenner et al. [25]. Relative survival equals the ratio of the observed probability of survival to the survival in the general population, here the population of North Rhine-Westphalia, given the same age, sex, and calendar period (expected survival).

\section{Results}

\section{Characteristics of the MEC cohorts}

The HRC cohort comprised 167 patients, all of which had the primary tumor surgically resected. Only patients with
G3-tumors underwent concurrent neck dissection, some of which also received adjuvant radiotherapy. Seven patients (4\%) had regional neck metastases (N1 or N3) at the time of presentation, one of these G3-tumors was positive for the CRTC1-MAML2 fusion. In addition, in seven cases (one G2- and six G3-MECs), tumor residues were discovered at the margins (R1). In 88 patients (53\%), complete removal of the tumor was unequivocally confirmed (R0). In the remaining cases, all but one derived from minor salivary glands, doubts were raised $(n=72)$ with regard to the margins and they were accordingly reported to the clinicians as RX.

In the LKR-NRW cohort, all patients $(\mathrm{n}=384)$ were surgically treated and the age-standardized incidence rate was $0.16(\mathrm{SE}=0.01)$ per 100,000 person-years for both, men and women, during the period 2007-2017. The grading-specific sex ratios ( $\mathrm{m}$ to $\mathrm{f}$ ) of the age-standardized incidence rates were $0.73,1.05$, and 1.75 for G1-, G2-, and G3-MECs, respectively. In both cohorts, tumors graded as G1 were most frequent.

Based on the Brandwein grading system (reevaluated after initial AFIP grading), 127 of 167 patients in the HRC cohort had G1-, 16 had G2-, and 24 had G3-tumors. Overall, $158(95 \%)$ of the tumors were classified as low-stage (pT1/pT2) tumors and nine as high-stage (>pT2) tumors. The low- versus high-stage tumors were distributed differently across the different tumor grades, pT1/pT2: $126 \mathrm{G1}$-, 13 G2-, and 20 G3-tumors versus > pT2: 1 G1-, 3 G2-, and 5 G3-tumors. Recurrences occurred in patients with G1$(n=3)$ and G2-tumors $(n=2)$, all patients recovered from disease after repeated surgery. Four of these five recurrent G1/G2-MECs were positive for the CRTC1-MAML2 fusion. Regardless of the grading system used, none of the G1- and G2-MECs developed distant metastases during follow-up and all these patients survived. In contrast, the three patients with G3-tumors (all fusion-negative, and G3 according to either the AFIP or Brandwein systems) progressed (one local and four lymph node events), and died with metastatic spread to internal organs.

In the HRC cohort, 20 of $167(12 \%)$ patients were aged 30 years or younger, and eight were younger than 18 years at the time of diagnosis. Among the 20 cases, 19 were G1- and only one was a G3-MEC. All MECs were classified as pT1- or pT2-tumors except for one case that was pT4. All 20 cases were CRTC1/3-MAML2 fusion-positive. In the follow-up cohort, all patients $(n=10)$ were free of disease and remained alive, including the two abovementioned patients with high-grade/high-stage MEC (Table 1). In the LKR-NRW cohort, 34 of $384(9 \%)$ patients were aged 30 years or younger, including 12 younger than 18 years at the time of diagnosis. Twenty-five of these had G1-/G2and two G3-tumors; for seven cases, no grade was available. Nineteen MECs were classified as pT1- or pT2-tumors and seven as $>$ pT2; for the remaining eight cases, the stage was 
unknown. All patients were alive at follow-up except for one patient who died of pancreatic cancer.

\section{Inter-rater agreement of the two grading systems}

We evaluated the inter-rater agreement between two pathologists on the dichotomized grading (G1/G2 versus G3) of 155 cases. The prevalence of G3-tumors according to pathologist TL and pathologist WB were 9.7\% and 9.0\%, respectively. The overall observed and weighted kappa agreements between the pathologists based on the AFIP system were 0.97 (95\% CI: 0.93-0.99) and 0.81 (95\% CI: 0.65-0.97), respectively. The corresponding agreements based on the Brandwein system were 0.96 (95\% CI: 0.92-0.99) and 0.83 (95\% CI: 0.71-0.96), respectively. The kappa agreements were lower for the AFIP than for the Brandwein system among cases derived from major salivary glands $(0.68,95 \%$ CI: $0.39-0.97$ versus $0.89,95 \%$ CI: $0.74-1.0)$ and among patients aged $0-49$ years $(0.66,95 \%$ CI: $0.04-0.96$ versus $0.79,95 \%$ CI: $0.40-1.0)$. Among the minor salivary gland MECs, the kappa agreement was higher for the AFIP than for the Brandwein system (0.93, 95\% CI: $0.79-1.0$ versus 0.77, 95\% CI: 0.56-0.99) (Supplementary Table).

\section{Concordance of the AFIP and Brandwein grading systems}

The concordance of grading based on the AFIP and the Brandwein systems was $94.8 \%$ and $91.6 \%$ for pathologist $\mathrm{TL}$ and WB, respectively. The Brandwein grading tended to produce a higher percentage of G3-tumors compared to the AFIP system (Table 2).

\section{CRTC1/3-MAML2 fusion status}

In total, 131 of 167 cases (78.4\%) from the HRC cohort were positive for CRTC1/3-MAML2 fusions (Table 3). Fusions were found in 115 G1-, nine G2-, and seven G3-tumors. Ninety-four of the fusion-positive patients had pT1-, 35 pT2-, one pT3-, and one pT4-disease. Of the 131 fusionpositive patients, 78 were females and 53 were males.

In the HRC follow-up cohort, 47 of the 60 MECs (78.3\%) were fusion-positive. G1-G2-tumors had a 3.0-fold prevalence of the fusion compared to G3-tumors (prevalence ratio $3.0,95 \% \mathrm{CI}: 1.6-5.6)$. The fusion was slightly more prevalent among tumors staged pT1 compared to higher stages (prevalence ratio 1.2, 95\% CI: 1.0-1.5). All young patients $(\leq 30 \mathrm{y}, \mathrm{n}=20)$ were fusion-positive. Three oncocytic MECs were G1 and fusion-positive (Fig. 1a and b), one clear cell MEC was G1 and fusion-negative, and one recurrent Warthin-like MEC was G2 and fusion-positive (Fig. 1a). Of the two noninvasive G3-MEC-ex-pleomorphic adenomas (MEC-ex-PAs), one was fusion-positive (Fig. 1c and d). Only two MECs (both G1) were positive for the CRTC3MAML2 fusion variant.

\section{Survival}

The estimated 5-year cumulative probability of progressionfree survival (PFS) in the HRC follow-up cohort $(\mathrm{n}=60)$ was $86 \%(\mathrm{SE}=0.05)$. The probability was considerably lower for high-grade tumors $(50 \%, \mathrm{SE}=0.23)$ than for low-grade tumors $(91 \%, \mathrm{SE}=0.04)$. The PFS probabilities for G1-, G2-, and G3-graded cases were 92\% ( $\mathrm{SE}=0.04)$, $75 \%(\mathrm{SE}=0.21)$, and $50 \%(\mathrm{SE}=0.23)$, respectively. Stagespecific PFS was $88 \%(\mathrm{SE}=6 \%)$ and $91 \%(\mathrm{SE}=9 \%)$ for pT1- and pT2-tumors, respectively. Although based on small numbers, PFS was considerably lower for pT3-tumors $(33 \%, \mathrm{SE}=27 \%)$. PFS was higher among patients with the CRTC1/3-MAML2 fusion (90\%, $\mathrm{SE}=5 \%)$ compared to fusion-negative patients (73\%, SE $=14 \%$ ) (Fig. 2).

Among the 332 cases from the LKR-NRW cohort with grading and follow-up available, the absolute 5-year survival for G1- $(n=178), G 2-(n=73)$, and G3- $(n=81)$ tumors were $87.7 \%(\mathrm{SE}=3.3), 77.4 \%(\mathrm{SE}=7.0)$, and $40.2 \%$ $(\mathrm{SE}=7.3)$, respectively. The corresponding relative survival estimates were 93.5\% ( $\mathrm{SE}=3.6), 81.6 \%(\mathrm{SE}=7.7)$, and $47.1 \%(\mathrm{SE}=8.5)$, respectively. The survival trends for G1- and G2-MEC patients were very similar, whereas the survival for G3-MEC patients were considerably lower during the 5 years of follow-up (Fig. 3a). The survival curves of patients with MEC of major salivary glands closely resembled those of the complete cohort with a markedly worse prognosis for G3-tumors compared to G1-tumors (Fig. 3b). Among minor salivary gland MECs, patients with G1-tumors had a relative survival of about $100 \%$, whereas the relative survival of patients with G2- and G3-tumors were much worse (Fig. 3c).

With regard to pT-stage, the survival analysis showed a similar picture. The survival trend for pT1-staged MECs within the complete cohort was excellent and for pT2-tumors good, whereas the survival for $\mathrm{pT} 3 / \mathrm{pT} 4$-staged MECs were considerably lower during the last 3 years of follow-up (Fig. 3d). The survival curves of patients with major salivary gland MECs closely resembled those of the complete cohort (Fig. 3e). In patients with minor salivary gland MEC, the relative survival of pT3/pT4-staged tumors was worse during the 5 years of follow-up (Fig. 3f).

\section{Discussion}

In this study, we have investigated clinical, histological, and molecular predictors of survival of MEC patients in two large patient cohorts, one from the HRC pathology $(n=167)$ and one from the population-based LKR-NRW cancer 
Table 1 Clinicopathologic characteristics of the Hamburg Salivary Gland Reference Centre (HRC) and Cancer Registry of North Rhine Westfalia (LKR-NRW) cohorts

\begin{tabular}{|c|c|c|c|}
\hline & $\begin{array}{l}\text { HRC overall } \\
\mathrm{n}=167(\%)^{\mathrm{a}}\end{array}$ & $\begin{array}{l}\text { HRC follow-up } \\
\mathrm{n}=60(\%)^{\mathrm{a}}\end{array}$ & $\begin{array}{l}\text { LKR-NRW } \\
\mathrm{n}=384(\%)^{\mathrm{a}}\end{array}$ \\
\hline Time period & $2007-2020$ & $2007-2020$ & 2007-2017 \\
\hline \multicolumn{4}{|l|}{ Age (years) } \\
\hline Mean/median (range) & $51.3 / 52(4-90)$ & $50.5 / 53.5(4-84)$ & $58.6 / 61(4-94)$ \\
\hline$\leq 18$ & $8(5)$ & $8(13)$ & $12(3)$ \\
\hline $19-30$ & $12(7)$ & $2(3)$ & $22(6)$ \\
\hline $31-49$ & $58(35)$ & $16(27)$ & $88(23)$ \\
\hline$\geq 50$ & $89(53)$ & $34(57)$ & $262(68)$ \\
\hline \multicolumn{4}{|l|}{ Sex } \\
\hline Male & $75(45)$ & $32(53)$ & $186(48)$ \\
\hline Female & $92(55)$ & $28(47)$ & $198(52)$ \\
\hline \multicolumn{4}{|l|}{ Primary site } \\
\hline Major gland & $75(45)$ & $28(47)$ & $236(61)$ \\
\hline Minor gland & $92(55)$ & $32(53)$ & $148(39)$ \\
\hline \multicolumn{4}{|l|}{ CRTC1/3-MAML2 } \\
\hline Positive & $131^{\mathrm{b}}(78)$ & $47(78)$ & - \\
\hline Negative & $36(22)$ & $13(22)$ & - \\
\hline \multicolumn{4}{|l|}{ Tumor grade } \\
\hline G1 & $127(76)$ & $47(78)$ & $178(46)$ \\
\hline G2 & $16(10)$ & $5(8)$ & $73(19)$ \\
\hline G3 & $24(14)$ & $8(13)$ & $81(21)$ \\
\hline Not reported & & & $52(14)$ \\
\hline \multicolumn{4}{|l|}{ pT-stage ${ }^{c}$} \\
\hline $\mathrm{T} 1$ & $113(68)$ & $36(60)$ & $132(34)$ \\
\hline $\mathrm{T} 2$ & $45(27)$ & $21(53)$ & $83(22)$ \\
\hline $\mathrm{T} 3$ & $3(2)$ & $1(2)$ & $45(12)$ \\
\hline $\mathrm{T} 4$ & $6(4)$ & $2(3)$ & $30(8)$ \\
\hline $\mathrm{TX}$ & - & - & $94(24)$ \\
\hline \multicolumn{4}{|l|}{$\mathrm{N}$-stage } \\
\hline N0 & $51(31)$ & $27(45)$ & $159(41)$ \\
\hline N1 & $6(4)$ & $2(3)$ & $22(6)$ \\
\hline N3 & $1(1)$ & $1(2)$ & $44(11)$ \\
\hline NX & $109(65)$ & $30(50)$ & $158(41)$ \\
\hline \multicolumn{4}{|l|}{ M-stage } \\
\hline M0 & $48(29)$ & $25(42)$ & $120(31)$ \\
\hline M1 & $1(1)$ & $1(2)$ & $6(2)$ \\
\hline MX & $118(71)$ & $34(57)$ & $258(67)$ \\
\hline \multicolumn{4}{|l|}{ R-status } \\
\hline R0 & $88(53)$ & $35(58)$ & - \\
\hline $\mathrm{R} 1$ & $7(4)$ & $2(3)$ & - \\
\hline $\mathrm{RX}$ & $72(43)$ & $23(38)$ & - \\
\hline Progression & $9(5)$ & $9(15)$ & - \\
\hline \multicolumn{4}{|l|}{ Deaths } \\
\hline Tumor-related & - & $3(5)$ & $25(7)$ \\
\hline Unrelated death & - & $5(8)$ & $92(24)$ \\
\hline
\end{tabular}

${ }^{a}$ Percentages have been rounded and may not total 100

${ }^{\mathrm{b}}$ Two cases with CRTC3-MAML2 fusion

c8th AJCC Cancer Staging Manual 
Table 2 Grading of 155 MECs according to the AFIP and Brandwein systems by two blinded pathologists

\begin{tabular}{|c|c|c|c|c|c|c|c|c|}
\hline \multirow[t]{3}{*}{ Pathologist TL } & \multicolumn{6}{|c|}{ Brandwein } & \multirow{3}{*}{$\begin{array}{l}\text { Overall } \\
\mathrm{N}\end{array}$} & \multirow[t]{3}{*}{$\%$} \\
\hline & \multicolumn{2}{|l|}{ G1 } & \multicolumn{2}{|l|}{$\mathrm{G} 2$} & \multicolumn{2}{|l|}{ G3 } & & \\
\hline & $\mathrm{N}$ & $\%$ & $\mathrm{~N}$ & $\%$ & $\mathrm{~N}$ & $\%$ & & \\
\hline \multicolumn{9}{|l|}{ AFIP } \\
\hline G1 & 119 & 76.8 & 2 & 1.3 & 0 & 0.0 & 121 & 78.1 \\
\hline G2 & 0 & 0.0 & 13 & 8.4 & 6 & 3.9 & 19 & 12.3 \\
\hline G3 & 0 & 0.0 & 0 & 0.0 & 15 & 9.7 & 15 & 9.7 \\
\hline Overall & 119 & 76.8 & 15 & 9.7 & 21 & 13.5 & 155 & \\
\hline Concordanc & & & & 94.8 & & & & \\
\hline \multicolumn{9}{|l|}{ Pathologist WB } \\
\hline G1 & 120 & 77.4 & 6 & 3.9 & 3 & 1.9 & 129 & 83.2 \\
\hline $\mathrm{G} 2$ & 0 & 0.0 & 8 & 5.2 & 4 & 2.6 & 12 & 7.7 \\
\hline G3 & 0 & 0.0 & 0 & 0.0 & 14 & 9.0 & 14 & 9.0 \\
\hline Overall & 120 & 77.4 & 14 & 9.0 & 21 & 13.6 & 155 & \\
\hline Concordanc & & & & 91.6 & & & & \\
\hline
\end{tabular}

Percentages are cell percentages with denominator $n=155$ MECs

\begin{tabular}{|c|c|c|c|c|}
\hline & \multicolumn{2}{|c|}{ CRTC1/3-MAML2 fusion } & \multicolumn{2}{|c|}{$\begin{array}{l}\text { Prevalence ratio of } \\
\text { fusion presence and } \\
95 \% \mathrm{CI}^{*}\end{array}$} \\
\hline & Fusion-negative (\%) & Fusion-positive (\%) & Ratio & $95 \% \mathrm{CI}$ \\
\hline HRC overall & $36(21.6)$ & $131(78.4)$ & & \\
\hline \multicolumn{5}{|l|}{ Tumor grade } \\
\hline G1-G2 & 19 & $124(86.7)$ & 3.0 & $1.6-5.6$ \\
\hline G3 & 17 & $7(29.2)$ & Ref & \\
\hline \multicolumn{5}{|l|}{ pT-stage } \\
\hline $\mathrm{T} 1$ & 19 & $94(83.2)$ & 1.2 & $1.0-1.5$ \\
\hline$>\mathrm{T} 1$ & 17 & $37(68.5)$ & Ref & \\
\hline HRC follow-up & $13(21.7)$ & $47(78.3)$ & & \\
\hline \multicolumn{5}{|l|}{ Tumor grade } \\
\hline $\mathrm{G} 1-\mathrm{G} 2$ & 7 & $45(86.5)$ & 3.5 & $1.0-11.6$ \\
\hline G3 & 6 & $2(25.0)$ & Ref & \\
\hline \multicolumn{5}{|l|}{ pT-stage } \\
\hline $\mathrm{T} 1$ & 5 & $31(86.1)$ & 1.3 & $1.0-1.8$ \\
\hline$>\mathrm{T} 1$ & 8 & $16(66.7)$ & Ref & \\
\hline
\end{tabular}

${ }^{*} C I$, confidence interval
Table 3 Prevalence of the CRTC1/3-MAML2 fusion by grade and stage in the Hamburg Salivary Gland Reference Centre (HRC) overall $(n=167)$ and follow-up cohorts $(n=60)$ registry $(n=384)$. We present up-to-date survival estimates of MECs of the major and minor salivary glands. Survival is clearly worse among cases with a higher stage ( $>\mathrm{T} 2)$ and grade (G3), and absence of the CRTC1/3-MAML2 fusion gene. Notably, MECs of young patients ( $\leq 30$ years) follow an entirely different clinical course. All 10 young patients in the HRC follow-up subgroup (all fusion-positive) and all 33 patients of the same age group in the LKR-NRW cohort had a favorable outcome independent of stage or grade. These observations are in line with previous studies showing that the CRTC1/3-MAML2 fusion occurs with a frequency of up to $100 \%$ in young patients and is associated with a favorable outcome, also in patients with high-stage ( $>$ pT2) and highgrade (G3) disease $[1,26]$.

Interestingly, as previously shown by Taylor et al., men with MECs of the major salivary glands have shorter survival than women which may be due to a higher proportion of G3-MECs among men compared to women [27]. In contrast to Taylor et al., we also studied the survival of patients with minor salivary gland MECs. In the LKR-NRW cohort, survival steadily decreased from G1 to G3 in minor salivary gland tumors. The G1-MECs showed a relative survival of 
Fig. 1 H\&E- and Alcian blue-stained MECs of the parotid gland. a Oncocytic variant with mixed solid and cystic architecture und typical hyper-eosinophilic phenotype, grade 1 (CRTC1-MAML2 positive; H\&E $\times 100)$. Inset: recurrent Warthin-like MEC of the palatal mucosa (CRTC1MAML2 positive; $\mathrm{H} \& \mathrm{E} \times 200$ ). b Same oncocytic variant as in a (Alcian blue $\times 200$ ). c Parotid gland MEC with mainly solid architecture and typical mixture of intermediate and mucusproducing cells (goblet cells). Clearly invasive phenotype with perineural growth, grade 3 (CRTC1-MAML2 negative, Alcian blue $\times 100$ ). d Same as in c showing different degrees of nuclear atypia $(H \& E \times 200)$
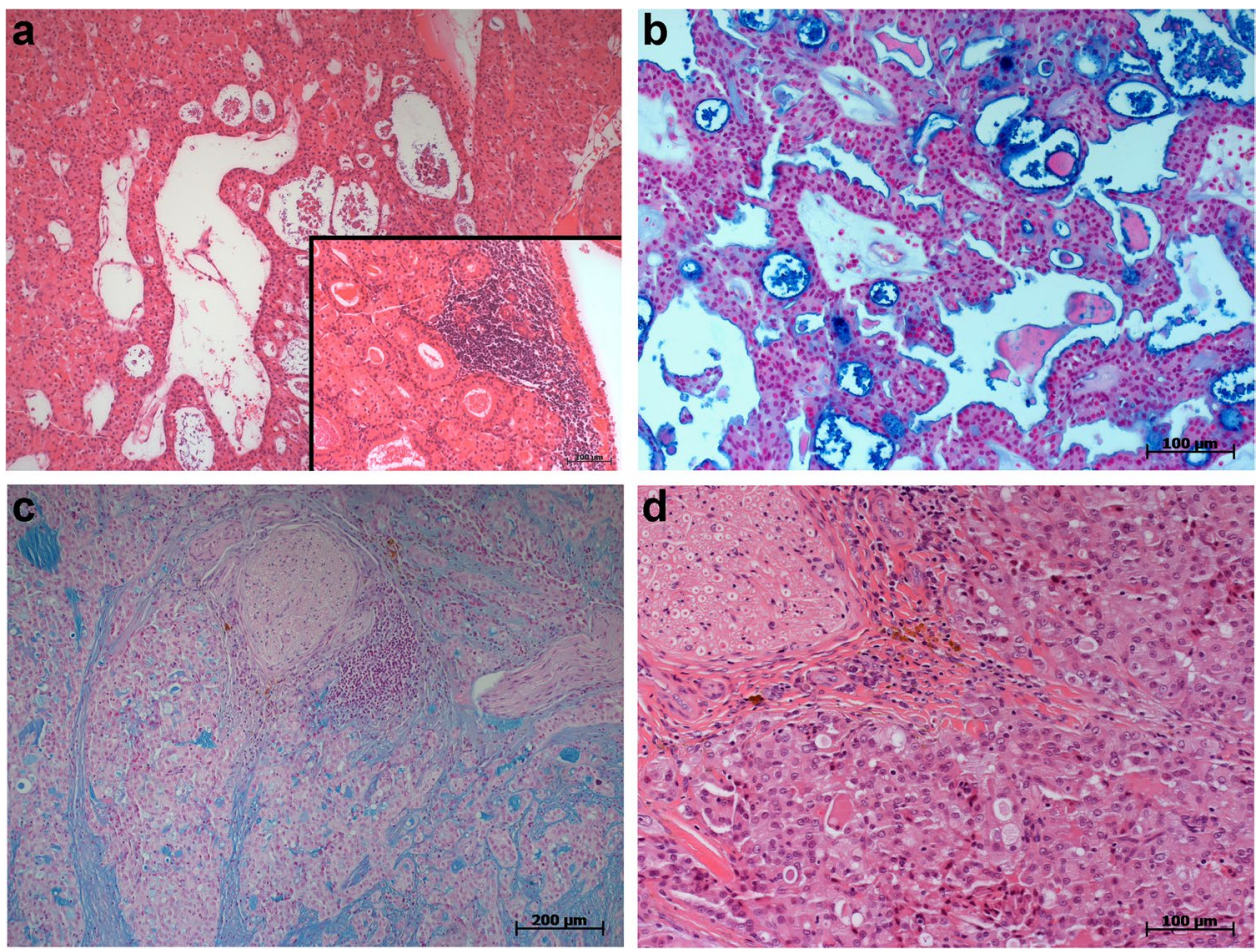
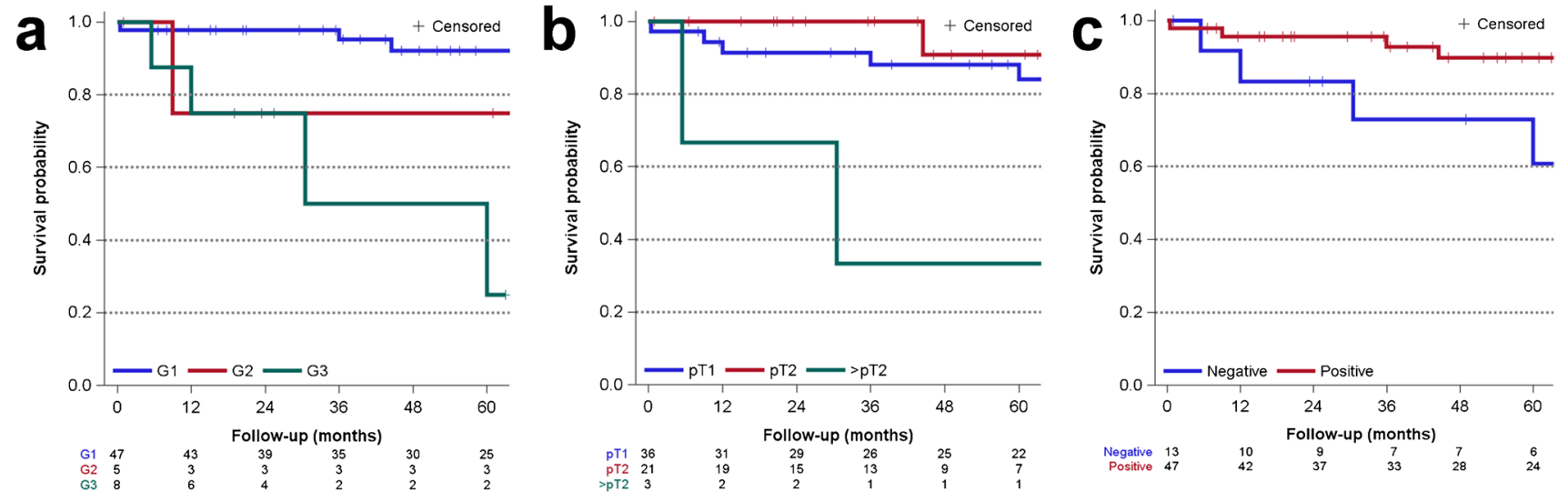

Fig. 2 Kaplan-Meier curves for the Hamburg Salivary Gland Reference Centre follow-up $(n=60)$ cohort. Progression-free survival according to a grade, b T-stage, and $\mathbf{c} C R T C 1 / 3-M A M L 2$ status

nearly $100 \%$, whereas the survival was significantly shorter for G2- and G3-tumors. This observation partly contradicts the study by Navale et al. which shows that minor salivary gland MECs have an increased tendency to metastasize even in the presence of histologic and molecular genetic features that would predict an indolent behavior [28]. It should, however, be noted that the number of cases analyzed is limited and that we lack data on the relative survival rate of different grades. Therefore, the survival rate of G1 patients might be higher than expected.

Overall, the inter-rater agreements between the AFIP and Brandwein grading systems were excellent. As expected, the Brandwein grading resulted in a higher percentage of G3-tumors, suggesting a possible increased risk of overtreatment [29]. Although this argument cannot be entirely excluded, our data show no grading-specific survival advantages for patients in the HRC cohort (re-graded according to the Brandwein system) compared with the LKR-NRW cohort (graded according to the AFIP system). Importantly, the presence of the CRTC1/3-MAML2 fusion gene was strongly associated with grading; G1/G2-tumors were more frequently fusion-positive compared to G3-tumors.

Our results corroborate the notion that the Brandwein grading system considers the invasive phenotype as an 

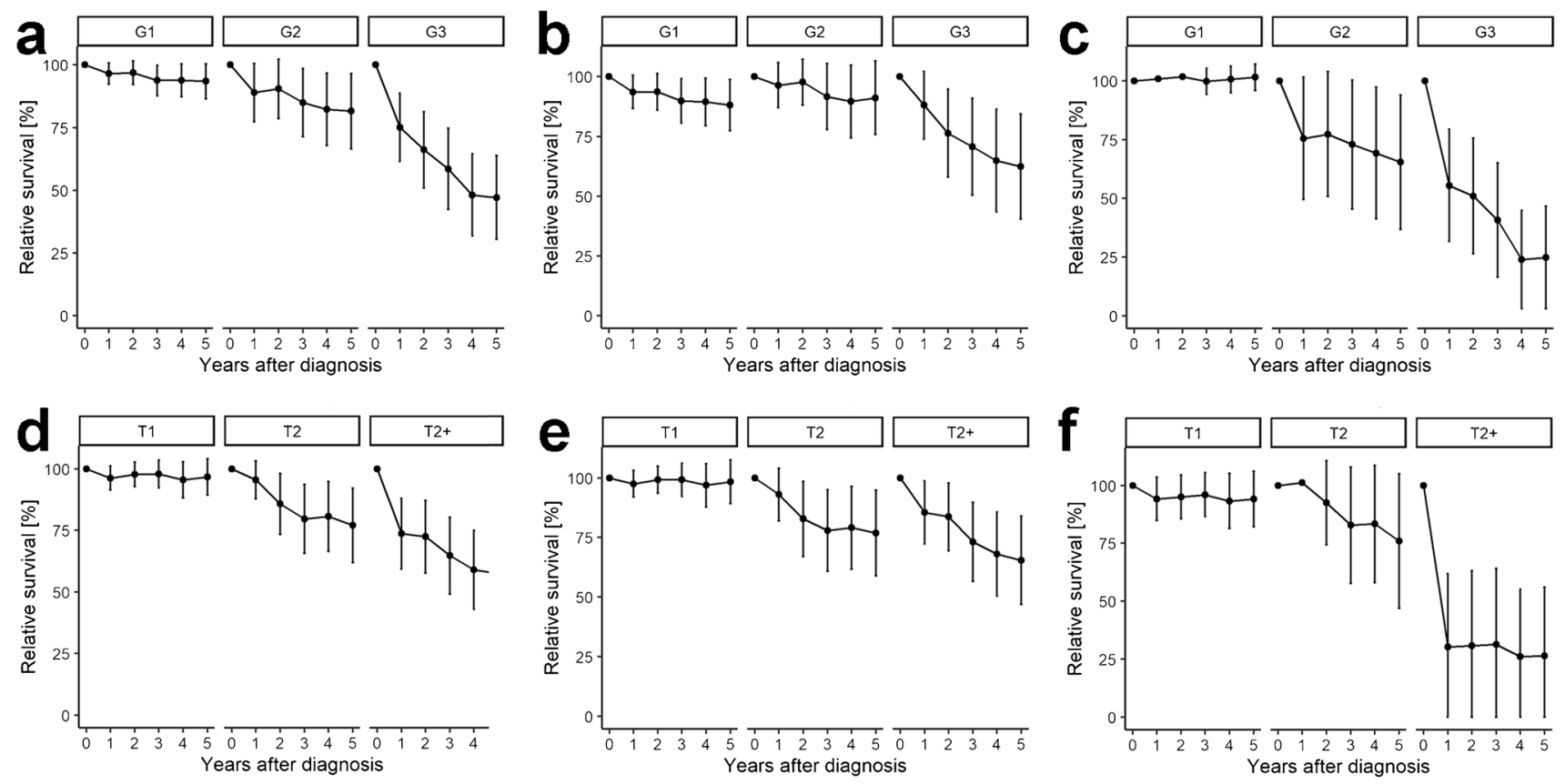

Fig. 3 Grading- and T-stage-specific relative survival of patients with salivary gland MECs in the LKR-NRW cohort (2007-2017). a and d Complete cohort. b and e Major salivary glands (ICD-10 C07 and C08). $\mathbf{c}$ and $\mathbf{f}$ Minor salivary glands (ICD-10 C00-C09 without C07 and C08)

additional and important grading criterion of MEC [30]. In our view, however, the inherent failures of this and other three-tiered grading systems are not resolved by using a binary modification (G1/G2 versus G3) as recommended by Cipriani et al. [31], because it does not eliminate the dilemma of a grey zone within the G1/G2-subgroups. This dilemma gets even more pronounced when looking separately at the survival of MECs of the major and minor salivary glands. The survival of patients with G2-MECs of the major glands was very similar to that of patients with G1-tumors. For patients with minor gland MECs, the survival declined steadily from G1- to G3-tumors. One explanation for this observation is that tumors of the minor glands are diagnostically more challenging, since they are almost invariably removed in multiple fragments to preserve anatomical and functional structures. This predicament not only compromises the quality of the histological diagnosis, but may also lead to an increase in the proportion of MECs graded as G2/G3. It also elicits doubts about clear margins of the resection specimens, which explains the high number of RX-cases in the HRC cohort.

Only two MECs were initially misinterpreted in the HRC cohort, one recurrent Warthin-like MEC of the palate (G2 and fusion-positive) and one adenocarcinoma with a minor mucinous component (G3 and fusion-negative). The latter was subsequently excluded after reevaluation because of its exclusive luminal phenotype. These observations are in line with previous studies and establish the value of $C R T C 1 / 3$ $M A M L 2$ fusion testing for diagnostic purposes [16, 17, 32].
This is not only true for the identification of bona fide carcinomas, but also for the differential diagnosis of benign tumors such as oncocytomas and Warthin tumors (MEClike variants) and for certain cystic lesions (congenital or acquired) with mucous metaplasia [13, 33-40]. In the HRC cohort, we noticed three oncocytic MEC variants, one clear cell variant, one Warthin-like variant, and two noninvasive MEC-ex-PA. Among these seven cases, five were positive for CRTC1-MAML2, including the abovementioned recurrent Warthin-like MEC of the palate. Our data clearly demonstrates that most G1- and G2-MECs are fusion-positive, whereas G3-MECs are mostly negative $[16,17]$. We found only two MECs with the CRTC3-MAML2 fusion variant, which confirms the rarity of this fusion [18, 19]. Collectively, our findings further emphasize previous observations from smaller series of MECs that the presence of the CRTC1/3-MAML2 fusion is associated with favorable clinical features, low-grade tumor histology, and a good prognosis $[15-17,19,20]$.

It should be emphasized that the differential diagnosis of G3-MECs is difficult even for experienced head and neck pathologists. Misinterpretations may occur when the number of mucous-producing cells is low or when these cells are hidden in structures of more or less undifferentiated squamous cells, leading to the diagnosis of, in particular, squamous cell carcinoma. Other differential diagnoses to consider are, for example, salivary duct carcinomas $[17,20]$ and adenosquamous carcinomas (the latter is not included in the latest WHO Classification of Head and Neck Tumors 
[2]). Interestingly, two recent studies of adenosquamous carcinomas of the pancreas showed that a considerable number of these cases ( $43.2 \%$ and $36 \%$ ), in addition to the classical pancreatic ductal adenocarcinoma component, also contained a high-grade MEC component [41, 42]. MAML2 fusion gene testing in one of these cohorts revealed that all tumors were fusion-negative [42]. These types of mixed carcinomas were never seen in the present G3 salivary MECs.

We are fully aware that the combination of a populationbased (LKR-NRW) and a consultation-based series (HRC) is unusual and carries potential biases. However, both cohorts are coherent since all pathologists used the same diagnostic principles and AFIP grading rules (trained in courses by the German Section of the IAP over decades). Thus, we conclude that the two cohorts are much more homogeneous than initially expected, with the possible exception of G2-MECs of minor glands which more often were classified as G3-tumors in the LKR-NRW-series. Finally, re-grading of the MECs in the HRC cohort using the Brandwein system (initially graded using the AFIP system) resulted in no major changes in progression-free survival.

In summary, our findings demonstrate that both the AFIP and Brandwein grading systems reflect the clinical behavior of G1- and G3-MECs quite well. For the challenging G2-tumors, we recommend that molecular testing for the CRTC1/3-MAML2 fusion is performed. Our findings show that detection of the fusion provides useful information for diagnosis, albeit it is not a powerful predictor of outcome. We conclude that CRTC1/3-MAML2 testing is a useful adjunct to histologic scoring of MECs and for pinpointing tumors with poor prognosis with higher precision, thus avoiding overtreatment. Continued clinical and molecular studies of large and well-characterized patient cohorts may eventually lead to the development of new clinical guidelines for the management of MEC patients.

Supplementary Information The online version contains supplementary material available at https://doi.org/10.1007/s00428-021-03146-x.

Acknowledgements This study was dedicated to Professor Dr. Gerhard Seifert $\dagger$ on behalf of his 100 birthday.

Author contribution Design of the study: all authors. Data collection: AF, SW, PT, MF, RF, AStang, FO, LK, WB, and TL. Pathologic evaluation: WB, KT, and TL. Data interpretation: AF, SW, PT, RF, AS, AStang, GS, WB, KT, and TL. Statistics: PT, AStang, and FO. Article writing: AF, AS, PT, AStang, GS, and TL. Read and revised the paper, and agreed with the final version of the paper: all authors.

Funding Open access funding provided by University of Gothenburg. AStang receives a grant from the German Federal Ministry of Education and Science (BMBF), grant number 01ER1704. AF is funded by a grant to GS from the Swedish state under the agreement between the Swedish government and the country councils, the ALF-agreement (ALFGBG-721711). This study was funded by the Institute of Hematopathology and the Gerhard Seifert-Reference Center, Hamburg,
Germany. The epidemiological cancer registry is permanently funded by the state of North Rhine-Westphalia (Germany) and covers all operating costs of the epidemiological registry.

Data Availability HRC: The use of clinical data and archived diagnostic leftover tissues for research purposes has been approved by local laws (HmbKHG, §12,1) and by the local ethics committee (Ethics Commission Hamburg, PV5412). All work has been carried out in compliance with the Helsinki Declaration. Because of data protection regulations in Germany, data of the HRC can only be made available upon request with justification.

NRW: In accordance with the State Cancer Registry Act of the State of North Rhine-Westphalia, data from the registry can only be made available upon request with justification.

Code availability Not applicable.

\section{Declarations}

Ethics approval The approval of our study was obtained from the regional Ethics Committee Hamburg, Germany (PV5412).

Consent to participate Participants of the HRC follow-up cohort provided written informed consent.

Consent for publication Participants of the HRC follow-up cohort provided written informed consent.

Competing interests The authors declare they have no competing interests.

Open Access This article is licensed under a Creative Commons Attribution 4.0 International License, which permits use, sharing, adaptation, distribution and reproduction in any medium or format, as long as you give appropriate credit to the original author(s) and the source, provide a link to the Creative Commons licence, and indicate if changes were made. The images or other third party material in this article are included in the article's Creative Commons licence, unless indicated otherwise in a credit line to the material. If material is not included in the article's Creative Commons licence and your intended use is not permitted by statutory regulation or exceeds the permitted use, you will need to obtain permission directly from the copyright holder. To view a copy of this licence, visit http://creativecommons.org/licenses/by/4.0/.

\section{References}

1. Locati LD, Collini P, Imbimbo M, Barisella M, Testi A, Licitra LF, Loning T, Tiemann K, Quattrone P, Bimbatti E, Chiaravalli S, Casanova M, Tamborini E, Carta R, Gasparini P, Guzzo M, Massimino M, Ferrari A (2017) Immunohistochemical and molecular profile of salivary gland cancer in children. Pediatr Blood Cancer 64(9). https://doi.org/10.1002/pbc.26468

2. El-Naggar AK, Grandis JR, Slootweg PJ, Chan JKC, Takata T (2017) WHO Classification of Tumours of the Head and Neck. WHO/IARC Classification of Tumours of the Head and Neck, 4th edn. Lyon: IARC Press

3. Kleinsasser O (1969) Mucoepidermoid tumors of salivary glands. Arch Klin Exp Ohren Nasen Kehlkopfheilkd 193(2):171-189. https://doi.org/10.1007/BF00401704

4. Seifert G (1972) The epithelial tumors of the salivary glands. Fortschr Kiefer Gesichtschir 15:2-18 
5. Seifert G, Sobin LH (1991) Histological typing of salivary gland tumours. World Health Organization. International histological classification of tumours, 2nd edition edn. Berlin-Heidelberg-New York: Springer. https://doi.org/10.1007/978-3-642-84506-2

6. Goode RK, Auclair PL, Ellis GL (1998) Mucoepidermoid carcinoma of the major salivary glands: clinical and histopathologic analysis of 234 cases with evaluation of grading criteria. Cancer 82(7):1217-1224

7. Auclair PL, Goode RK, Ellis GL (1992) Mucoepidermoid carcinoma of intraoral salivary glands evaluation and application of grading criteria in 143 cases. Cancer 69(8):2021-2030

8. Stenman G, Persson F, Andersson MK (2014) Diagnostic and therapeutic implications of new molecular biomarkers in salivary gland cancers. Oral Oncol 50(8):683-690. https://doi.org/10. 1016/j.oraloncology.2014.04.008

9. Brandwein MS, Ivanov K, Wallace DI, Hille JJ, Wang B, Fahmy A, Bodian C, Urken ML, Gnepp DR, Huvos A, Lumerman H, Mills SE (2001) Mucoepidermoid carcinoma: a clinicopathologic study of 80 patients with special reference to histological grading. Am J Surg Pathol 25(7):835-845. https://doi.org/10.1097/00000 478-200107000-00001

10. Ellis G, Auclair P (1996) Tumors of the salivary glands. In: Atlas of tumor pathology. vol 3rd. Washington DC: Armed Forces Institute of Pathology

11. Skalova A, Stenman G, Simpson RHW, Hellquist H, Slouka D, Svoboda T, Bishop JA, Hunt JL, Nibu KI, Rinaldo A, Vander Poorten V, Devaney KO, Steiner P, Ferlito A (2018) The role of molecular testing in the differential diagnosis of salivary gland carcinomas. Am J Surg Pathol 42(2):e11-e27. https://doi.org/10. 1097/PAS.0000000000000980

12. Nordkvist A, Gustafsson H, Juberg-Ode M, Stenman G (1994) Recurrent rearrangements of 11q14-22 in mucoepidermoid carcinoma. Cancer Genet Cytogenet 74(2):77-83. https://doi.org/10. 1016/0165-4608(94)90001-9

13. Enlund F, Behboudi A, Andren Y, Oberg C, Lendahl U, Mark J, Stenman G (2004) Altered Notch signaling resulting from expression of a WAMTP1-MAML2 gene fusion in mucoepidermoid carcinomas and benign Warthin's tumors. Exp Cell Res 292(1):2128. https://doi.org/10.1016/j.yexcr.2003.09.007

14. Tonon G, Modi S, Wu L, Kubo A, Coxon AB, Komiya T, O’Neil K, Stover K, El-Naggar A, Griffin JD, Kirsch IR, Kaye FJ (2003) $\mathrm{t}(11 ; 19)(\mathrm{q} 21 ; \mathrm{p} 13)$ translocation in mucoepidermoid carcinoma creates a novel fusion product that disrupts a Notch signaling pathway. Nat Genet 33(2):208-213. https://doi.org/10.1038/ng1083

15. Behboudi A, Enlund F, Winnes M, Andren Y, Nordkvist A, Leivo I, Flaberg E, Szekely L, Makitie A, Grenman R, Mark J, Stenman G (2006) Molecular classification of mucoepidermoid carcinomas-prognostic significance of the MECT1-MAML2 fusion oncogene. Genes Chromosomes Cancer 45(5):470-481. https:// doi.org/10.1002/gcc.20306

16. Fehr A, Meyer A, Heidorn K, Röser K, Löning T, Bullerdiek J (2009) A link between the expression of the stem cell marker HMGA2, grading, and the fusion CRTC1-MAML2 in mucoepidermoid carcinoma. Genes Chromosomes Cancer 48(9):777-785. https://doi.org/10.1002/gcc.20682

17. Jee KJ, Persson M, Heikinheimo K, Passador-Santos F, Aro K, Knuutila S, Odell EW, Makitie A, Sundelin K, Stenman G, Leivo I (2013) Genomic profiles and CRTC1-MAML2 fusion distinguish different subtypes of mucoepidermoid carcinoma. Mod Pathol 26(2):213-222. https://doi.org/10.1038/modpathol.2012.154

18. Fehr A, Roser K, Heidorn K, Hallas C, Loning T, Bullerdiek J (2008) A new type of MAML2 fusion in mucoepidermoid carcinoma. Genes Chromosomes Cancer 47(3):203-206. https://doi. org/10.1002/gcc.20522

19. Nakayama T, Miyabe S, Okabe M, Sakuma H, Ijichi K, Hasegawa Y, Nagatsuka H, Shimozato K, Inagaki H (2009)
Clinicopathological significance of the CRTC3-MAML2 fusion transcript in mucoepidermoid carcinoma. Mod Pathol 22(12):1575-1581. https://doi.org/10.1038/modpathol.2009.126

20. Seethala RR, Dacic S, Cieply K, Kelly LM, Nikiforova MN (2010) A reappraisal of the MECT1/MAML2 translocation in salivary mucoepidermoid carcinomas. Am J Surg Pathol 34(8):1106-1121. https://doi.org/10.1097/PAS.0b013e3181de3021

21. Seethala RR, Chiosea SI (2016) MAML2 status in mucoepidermoid carcinoma can no longer be considered a prognostic marker. Am J Surg Pathol 40(8):1151-1153. https://doi.org/10.1097/PAS. 0000000000000676

22. Koch-Institut R (2019) Krebs in Deutschland für 2015/2016. vol 12. Robert Koch Institut (Hrsg) und Gesellschaft der epidemiologischen Krebsregister in Deutschland e.V. (Hrsg); Berlin. https:// doi.org/10.17886/rkipubl-2017-007

23. Amin MB, Edge S, Greene F, Byrd DR, Brookland RK, Washington MK, Gershenwald JE, Compton CC, Hess KR, Sullivan DC, Jessup JM, Brierley JD, Gaspar LE, Schilsky RL, Balch CM, Winchester DP, Asare EA, Madera M, Gress DM, Meyer LR (eds) (2017) AJCC Cancer Staging Manual, 8th edn. New York: Springer International Publishing

24. Brenner H, Hakulinen T (2009) Up-to-date cancer survival: period analysis and beyond. Int J Cancer 124(6):1384-1390. https://doi. org/10.1002/ijc. 24021

25. Brenner H, Gefeller O, Hakulinen T (2004) Period analysis for 'up-to-date' cancer survival data: theory, empirical evaluation, computational realisation and applications. Eur J Cancer 40(3):326-335. https://doi.org/10.1016/j.ejca.2003.10.013

26. Techavichit P, Hicks MJ, Lopez-Terrada DH, Quintanilla NM, Guillerman RP, Sarabia SF, Sayeed H, Nuchtern JG, Paulino AC, Muscal JA, Okcu MF, Chintagumpala M (2016) Mucoepidermoid carcinoma in children: a single institutional experience. Pediatr Blood Cancer 63(1):27-31. https://doi.org/10.1002/pbc.25681

27. Taylor ZC, Kaya EA, Bunn JD, Guss ZD, Mitchell BJ, Fairbanks RK, Lamoreaux WT, Wagner AE, Peressini BJ, Lee CM (2020) Overall and cause-specific survival for mucoepidermoid carcinoma of the major salivary glands: analysis of 2210 patients. World J Clin Oncol 11(12):1029-1044. https://doi.org/10.5306/ wjco.v11.i12.1029

28. Navale P, Rooper LM, Bishop JA, Westra WH (2019) Mucoepidermoid carcinoma of the oropharynx: a tumor type with a propensity for regional metastasis unrelated to histologic grade. Hum Pathol 93:1-5. https://doi.org/10.1016/j.humpath.2019.08.014

29. Seethala RR (2009) An update on grading of salivary gland carcinomas. Head Neck Pathol 3(1):69-77. https://doi.org/10.1007/ s12105-009-0102-9

30. Nance MA, Seethala RR, Wang Y, Chiosea SI, Myers EN, Johnson JT, Lai SY (2008) Treatment and survival outcomes based on histologic grading in patients with head and neck mucoepidermoid carcinoma. Cancer 113(8):2082-2089. https://doi.org/10.1002/ cncr. 23825

31. Cipriani NA, Lusardi JJ, McElherne J, Pearson AT, Olivas AD, Fitzpatrick C, Lingen MW, Blair EA (2019) Mucoepidermoid carcinoma: a comparison of histologic grading systems and relationship to MAML2 rearrangement and prognosis. Am J Surg Pathol 43(7):885-897. https://doi.org/10.1097/PAS.0000000000001252

32. Okabe M, Miyabe S, Nagatsuka H, Terada A, Hanai N, Yokoi M, Shimozato K, Eimoto T, Nakamura S, Nagai N, Hasegawa Y, Inagaki H (2006) MECT1-MAML2 fusion transcript defines a favorable subset of mucoepidermoid carcinoma. Clin Cancer Res 12(13):3902-3907. https://doi.org/10.1158/1078-0432. CCR-05-2376

33. Chan RC, Chan JY (2014) Head and neck mucoepidermoid carcinoma: a curious association with second primary malignancy. Otolaryngol Head Neck Surg 151(5):797-801. https://doi.org/10. $1177 / 0194599814551131$ 
34. Fonseca FP, de Andrade BA, Lopes MA, Pontes HA, Vargas PA, de Almeida OP (2013) P63 expression in papillary cystadenoma and mucoepidermoid carcinoma of minor salivary glands. Oral Surg Oral Med Oral Pathol Oral Radiol 115(1):79-86. https://doi. org/10.1016/j.0ooo.2012.09.005

35. Lennerz JK, Perry A, Mills JC, Huettner PC, Pfeifer JD (2009) Mucoepidermoid carcinoma of the cervix: another tumor with the $\mathrm{t}(11 ; 19)$-associated CRTC1-MAML2 gene fusion. Am J Surg Pathol 33(6):835-843. https://doi.org/10.1097/PAS.0b013e3181 90cf5b

36. Wolfish EB, Nelson BL, Thompson LD (2012) Sinonasal tract mucoepidermoid carcinoma: a clinicopathologic and immunophenotypic study of 19 cases combined with a comprehensive review of the literature. Head Neck Pathol 6(2):191-207. https://doi.org/ 10.1007/s12105-011-0320-9

37. Fehr A, Roser K, Belge G, Loning T, Bullerdiek J (2008) A closer look at Warthin tumors and the $\mathrm{t}(11 ; 19)$. Cancer Genet Cytogenet 180(2):135-139. https://doi.org/10.1016/j.cancergencyto.2007.10. 007

38. Skalova A, Vanecek T, Simpson RH, Vazmitsel MA, Majewska H, Mukensnabl P, Hauer L, Andrle P, Hosticka L, Grossmann P, Michal M (2013) CRTC1-MAML2 and CRTC3-MAML2 fusions were not detected in metaplastic Warthin tumor and metaplastic pleomorphic adenoma of salivary glands. Am J Surg Pathol 37(11):1743-1750. https://doi.org/10.1097/PAS.0000000000 000065

39. Tirado Y, Williams MD, Hanna EY, Kaye FJ, Batsakis JG, ElNaggar AK (2007) CRTC1/MAML2 fusion transcript in high grade mucoepidermoid carcinomas of salivary and thyroid glands and Warthin's tumors: implications for histogenesis and biologic behavior. Genes Chromosomes Cancer 46(7):708-715. https://doi. org/10.1002/gcc. 20458

40. Winnes M, Enlund F, Mark J, Stenman G (2006) The MECT1MAML2 gene fusion and benign Warthin's tumor: is the MECT1MAML2 gene fusion specific to mucuepidermoid carcinoma? J Mol Diagn 8(3):394-395. author reply 395-396. https://doi.org/ 10.2353/jmoldx.2006.060020

41. Boecker J, Feyerabend B, Tiemann K, Buchwalow I, Wagner KC, Oldhafer KJ, Andruszkow J, Daniels T, Boessow T, Boecker W, Neumann UP (2020) Adenosquamous carcinoma of the pancreas comprise a heterogeneous group of tumors with the worst outcome: a clinicopathological analysis of 25 cases identified in 562 pancreatic carcinomas resected with curative intent. Pancreas 49(5):683-691. https://doi.org/10.1097/MPA.0000000000001548

42. Saeki K, Ohishi Y, Matsuda R, Mochidome N, Miyasaka Y, Yamamoto H, Koga Y, Maehara Y, Nakamura M, Oda Y (2018) "Pancreatic mucoepidermoid carcinoma" is not a pancreatic counterpart of CRTC1/3-MAML2 fusion gene-related mucoepidermoid carcinoma of the salivary gland, and may more appropriately be termed pancreatic adenosquamous carcinoma with mucoepidermoid carcinoma-like features. Am J Surg Pathol 42(11):14191428. https://doi.org/10.1097/PAS.0000000000001135

Publisher's note Springer Nature remains neutral with regard to jurisdictional claims in published maps and institutional affiliations. 